\title{
Ability of Children with Learning Disabilities and Children with Autism Spectrum Disorder to Recognize Feelings from Facial Expressions and Body Language
}

\author{
Alev Girli ${ }^{1} \&$ Sıla Doğmaz ${ }^{2, *}$ \\ ${ }^{1}$ Faculty of Education, Dokuz Eylul University, Izmir, Turkey \\ *Correspondence: Egitim Fakültesi, Dokuz Eylül Universitesi, İzmir, Türkiye. E-mail: sila.dogmaz@gmail.com \\ Received: February 14, $2018 \quad$ Accepted: March 6, 2018 Online Published: March 21, 2018 \\ doi:10.5430/wje.v8n2p10 \\ URL: https://doi.org/10.5430/wje.v8n2p10
}

\begin{abstract}
In this study, children with learning disability (LD) were compared with children with autism spectrum disorder (ASD) in terms of identifying emotions from photographs with certain face and body expressions. The sample consisted of a total of 82 children aged 7-19 years living in Izmir in Turkey. A total of 6 separate sets of slides, consisting of black and white photographs, were used to assess participants' ability to identify feelings -3 sets for facial expressions, and 3 sets for body language. There were 20 photographs on the face slides and 38 photographs on the body language slides. The results of the nonparametric Mann Whitney-U test showed no significant difference between the total scores that children received from each of the face and body language slide sets. It was observed that the children with LD usually looked at the whole photo, while the children with ASD focused especially around the mouth to describe feelings. The results that were obtained were discussed in the context of the literature, and suggestions were presented.
\end{abstract}

Keywords: facial expression, body language, learning disability, autism spectrum disorder, recognize feelings

\section{Introduction}

The issue of whether children with learning disabilities (LD) experience socio-emotional problems has been a focus of debate in the literature. Moreover, a consensus has been reached on the fact that the socio-emotional abilities have a central role in defining the disorder (American Psychiatric Association, 1994). The meta-analysis of Kavale and Forness (1996) provided support for this consensus by stating that $75 \%$ of children with LD exhibit deficiencies in social skills. The difficulties which the children with LD experience in characterizing social information processing were more emphasized than the emotional difficulties they experience (Arthur, 2003). Despite a limited research with LD, many researchers have found that children have difficulties in social skills as well as in academic areas (Dogmaz \& Girli, 2017; Meadan \& Halle, 2004; Kavale \& Mostert, 2004; Arthur, 2003; Gresham, 1992). It has been reported that such children have more problem behaviors than their normally developing (ND) peers, and that their positive behaviors in the social context are insufficient (Petti, Voelker, Share, Hayman-Abello, 2003). Additionally, the research showed that they are more likely to experience difficulty in interpreting emotional situations (Bryan, 1977 ) and that children with LD are less capable than their ND peers in skills of the theory of mind, which is defined as one's ability to symbolize other people's mental states such as thoughts, desires and opinions (Özen, 2015).

It is emphasized that there is a positive relationship between social competences of children, their theory of mind competences, and peer acceptance (Kavale \& Mostert, 2004). Because of the inadequacy of their interaction patterns, studies indicate that children with LD are at risk of being rejected by their peers (Bloom \& Heath, 2010; Bauminger, Edelsztein, Morash, 2005; McKenzie, Matheson, McKaskie, Hamilton, Murray, 2000). The ability to understand, recognize and express emotions from facial expressions is an important indicator of social functioning (Zuckerman \& Przewuzman, 1979). The literature shows that the lack of non-verbal social perception plays an important role in children and adolescents with LD's experiencing more socio-emotional distress than their normally developing (ND) peers (Bursuck, 1989; Spreen, 1988). The ability to distinguish feelings through the face and body is an important discriminator that influences children's general adaptations to school, sociometric status, popularity among other peers with normal development (ND), and social competence (Zuckerman \& Przewuzman, 1979). It is accepted that many children with LD have problems in social interaction. They tend to be rejected by their peers and lonely in their 
social context, especially because they show a lack of interaction with peers and adults (Elias, 2004). Moreover, these children have difficulty in reading non-verbal cues and other deliberate cues (McKleskey \& Pacchiano, 1994). Some problems may be related to children's learning disability. To exemplify, students with more severe cognitive impairments may be deprived of the social meaning of age-appropriate complex interactions. On the other hand, students with language impairment can understand social situations well, but may have difficulty in communicating effectively with others (McKleskey \& Pacchiano, 1994). The children with LD experience more difficulties than their ND peers because they have difficulty in interpreting the clues about tone of voice, facial and body expressions, and transferred emotional states (Bauminger et al., 2005). They are inadequate to express their emotional state correctly in social context (Petti et al., 2003). In addition, research revealed that they have difficulty in interpreting the intentions of others, cannot interpret the clues that will help them to recognize the emotions arising during communication, and therefore - as they lack ability to initiate interactions - they fail to demonstrate appropriate communication behaviors (Arthur, 2003; McKenzie et al., 2000; Nabuzoka \& Smith, 1999). Problems in interpersonal interaction also negatively affect children's social development. Especially young children with LD have been found to express sad and aggressive behaviors by isolating themselves from the social context (Sullivan, Vitello, Foster, 1988).

Ekman (1999), studying human face expressions, has suggested that there are six basic emotions: happy, sad, scared, angry, confused, and disgusted. In addition, Ekman (1999) considers that each emotion is a separate unit. Facial expressions, which are the manifestations of basic emotions, occur on the basis of various positional movements of facial muscles and the facial skin's deforming these movements (Dailey, Cottrell, Padgett, Adolphs, 2002; Ekman, 1999). Opinions on how feelings are perceived differ according to the description of feelings. "Categorical perception, where emotions are assumed to be discrete, views that different physical stimuli accompany each set of emotions. As a manifestation of each emotion, the subjective facial expressions include precise, bounded structural features. Another view suggests that emotions are not separate categories, but are continuous in a space. However, it is a topic of discussion that some emotions consist of categories separate from each other, while most emotional facial expressions consist of fuzzy facial expressions formed by a mixture of varying levels of more than one emotional category (Neth and Martinez, 2010; Dailey et al., 2002).

Social interaction and communication are based on correctly recognizing and responding to rapid fluctuations in others' emotional states (Nomi, Scherfeld, Friederichs, Schäfer, Franz, Wittsack, 2008). Emotions are understood through behaviors such as gestures, mimics, speech, prosody and mutual relationship, and the evaluation of internal state. Recognizing emotional facial expressions slowly develops from the first years of life and reaches the adult level with adolescence. Babies can distinguish different emotional expressions from the first months of life (Grelotti, Gauthier, Schultz, 2002). It is stated that the ability to distinguish expressions in infants is influenced by the presentation order, the familiarity rate with the expressions, and simple property differences (for example, the mouth is open/closed). In studies on the ability of children with LD to recognize emotions, happiness is the most easily recognized emotion in facial expressions. Moreover, such children can more easily identify the feelings of happiness, sadness and anger, which are more basic emotions, than confusion, disgust and fear, which are less common in the social context (Bauminger et al., 2005; Dimitrovsky, 1998; Holder \& Kirkpatrick, 1991). Because children are more likely to encounter objects that express happiness in stories and in pictures, children with LD were more likely to respond incorrectly than ND children, especially in the recognition of negative emotions. Additionally, children with LD confuse sad with angry, angry with disgusted, or neutral with sad face (Bauminger et al., 2005; Dimitrovsky, 1998; Holder \& Kirkpatrick, 1991).

In previous similar studies, children with LD were compared with their ND peers in terms of elapsing time to understand, recognize, and name emotions. Although studies show that both children with LD and children with autism spectrum disorder (ASD) have problems in the social context, no study could be found comparing them in terms of recognition of emotions (Kavale \& Mostert, 2004; Noens \& van Berckelaer-Onnes, 2004, Klin, Volkmar, Sparrow, Cicchetti, Rourke, 1995; Knott, Lewis, Williams, 1995; Gresham, 1992). As it is known, the children with ASD show significant delays and deterioration in understanding their and others' emotional expressions (Girli \& Sabırsı, 2011; Harms, Martin, Wallace, 2010; Schneider \& Goldstein, 2010; Atwood, 2000). Even in adulthood, many individuals with ASD have problems in recognizing complex emotions, regulating and expressing emotions, establishing eye contact, and face processing (Samson, Huber, Gross, 2012; McPartland, Webb, Keehn, Dawson, 2011, Pelphrey et al. 2002; Klin, Jones, Schultz, Volkmar \& Cohen, 2002; Baron-Cohen, 1995, 2003). Some researchers argue that autism is interrelated with learning disabilities (O'Brien \& Pearson, 2004). According to some researchers, autistic attributes are increasingly common among individuals with learning disabilities, on the other hand 50-60 percent of individuals with severe learning disability display the triad of 
impairments, namely social interaction, verbal and non-verbal communication, and imagination that is typical in autism (Wing \& Gould, 1979). Arguments continue as to whether LD and ASD are interrelated and whether they can be seen as different diagnoses. Nevertheless, while learning disability is characterized by wide-ranging delay, autism can de associated both with delay and deviation (Ghaziuddin, 2000).

The literature review reveals a lack of studies investigating children's and adolescents' recognition of facial expressions. These studies do not focus on facial and body combinations that are necessary to understand emotions as a whole (Petti et al., 2003; Dimitrovsky, Spector, Levy-Shiff, 2000). In Turkey, a study (Girli, 2016) comparing the levels of emotional recognition of children with LD and children with ASD in the 7-12 age group was found. This study will investigate the levels of emotional recognition of children with LD and ASD in a wider age range (7-19) and a larger sample, and will contribute to the literature in this sense. It should also be remembered that face expressions and body language are important nonverbal channels for communicating emotions (Petti et al., 2003; Dimitrovsky et al., 2000). Given the lack of studies and importance of face expressions and body language, this study will make an important contribution by directing attention of experts working in the field towards the need that social skills such as recognition of emotions, understanding of body language and non-verbal messages. The aim of this study was to determine the levels of understanding of children with LD in the 7-19 age group - specifically, their understanding of the six emotions (happy, sad, scared, angry, confused, and disgusted) conveyed by facial expressions and body language of the characters in photographs. Additionally, this study investigates similarities and differences between children with LD and their peers with ASD in terms of recognition of face expressions and body language.

\section{Method}

\subsection{Research Model}

The mixed research design was used in the study, in which quantitative and qualitative data were combined. In this study, children with ASD were compared with children with LD. The scores they received from correct answers were evaluated to compare the levels of recognition of feelings from face expressions and body language; hence, data were examined using a comparative survey model of the descriptive research methods (Büyüköztürk, 2017). The frequencies and percentages of the participant responses were examined. The similarities and differences in the forms of emotional processing of the children in the two diagnostic groups were investigated by analyzing the written records of the answers to the questions asked to reveal the clues they referred to recognize the emotions. This method was preferred because it allows for thorough and detailed data collection from the selected sample. Qualitative research techniques have a holistic approach and provide revealing perceptions by an inductive analysis (Yıldırım \& Şimşek, 2008).

\subsection{Participants}

The study group was formed from a total of 82 children aged from 7 to 19 who were receiving training at three centers in Izmir in Turkey, which provide training for individuals diagnosed with learning disabilities and autism spectrum disorders, and were allowed to participate in the study by their families. The condition to include in the study was that the children with LD had to be diagnosed by a team of specialists in the Children's Psychiatry Clinics and that their IQ scores were above 85.43 children diagnosed with LD who met these criteria were accepted to the study. When the autism spectrum disorder group was established, the condition was that the diagnosis was made at the Children's Psychiatry Clinics, and the level of language development had to be 6 years of age or older so that they could make explanations about emotions. 39 ASD-diagnosed children meeting these criteria were included in the study as a comparison group. All of the children were continuing to attend public schools through the inclusive education program. The children were members of middle-income civil servants and self-employed families residing in the districts of the provincial centers of Izmir. Distribution of the children participating in the study according to gender, age and class levels is presented in Table 1.

Table 1. Distribution of Surveyed Children by Age, Gender and Class Levels

\begin{tabular}{|c|c|c|c|c|c|c|c|c|c|c|c|c|c|c|c|c|}
\hline & \multicolumn{6}{|c|}{ Age } & \multicolumn{6}{|c|}{ Class } & \multicolumn{4}{|c|}{ Gender } \\
\hline & \multirow[t]{2}{*}{$\mathrm{N}$} & \multirow[t]{2}{*}{$\bar{x}$} & \multirow[t]{2}{*}{ SD } & \multirow[t]{2}{*}{ Range } & \multirow[t]{2}{*}{ Min. } & \multirow[t]{2}{*}{ Max. } & \multirow[t]{2}{*}{$\mathrm{N}$} & \multirow[t]{2}{*}{$\bar{x}$} & \multirow[t]{2}{*}{ SD } & \multirow[t]{2}{*}{ Range } & \multirow[t]{2}{*}{ Min. } & \multirow[t]{2}{*}{ Max. } & \multicolumn{2}{|c|}{ Male } & \multicolumn{2}{|c|}{ Female } \\
\hline & & & & & & & & & & & & & $\mathrm{f}$ & $\%$ & $\mathrm{f}$ & $\%$ \\
\hline LD & 43 & 11.14 & 2.651 & 11 & 8 & 19 & 43 & 5.05 & 2.380 & 10 & 2 & 12 & 27 & 62.8 & 16 & 37.2 \\
\hline ASD & 39 & 10.28 & 2.188 & 9 & 7 & 16 & 39 & 5.74 & 2.245 & 9 & 1 & 10 & 36 & 92.3 & 3 & 7.7 \\
\hline Total & 82 & & & & & & 82 & & & & & & 63 & & 19 & \\
\hline
\end{tabular}




\subsection{Data Collection Instruments}

In the study, a total of 6 separate sets of slides, consisting of black and white photographs, were used to assess participants' ability to identify feelings -3 sets for facial expressions, and 3 sets for body language. There were 20 photographs on the face slides and 38 photographs on the body language slides. Separate registration forms were used for each set. A single photo was used on each slide in all sets.

1st Face slide set: They were black and white photographs depicting face expressions of a woman's four basic emotional states. In each slide, there was a photo in the middle and two options written at the sides of the photo.

2nd Face slide set: Photos were used within a frame that included expressions of happy, frightened, angry, and sad that are the four basic emotions. Children were presented with four choices by asking "Is she happy, angry, frightened?" by pointing to each photo at random. The locations of the people in the photos changed with the slide. In every practice, the researcher changed the places as he named the feelings.

3rd Face slide set: They were black and white photographs depicting face expressions of a man's four basic emotional states. There were no writings expressing the names of the feelings.

1st Body language slide set: Black and white photographs of a woman's face and upper body were used. On each slide, a single photo was used, and no hints were added about emotion.

2nd Body language slide set: Black and white photographs of a child's body expressions were used. In the photographs, the face of the child, the upper part of the body and hands were visible.

3rd Body language slide set: Drawings of a child's body expressions were used. In the drawings, the face of the child, the upper part of the body and hands were visible.

\subsection{Procedures}

The practices were individually administered by the researchers to each child in the special training centers, and each practice lasted 20-30 minutes. First the sets of face slides followed by the sets of body language slides were administered. Children's responses to each photo were recorded and then scored as incorrect or correct using an answer key. Correct answers were scored as 1 point and incorrect answers as 0 points. How the children got this answer was assessed by the questions of "Of which part of the face/body did you look at to get this expression? What were the things/tips to help you find the answer?" The explanations made by the students were noted in the registration form, just as were, for use in the qualitative part of the study.

\subsection{Data Analysis}

A statistical analysis of the responses of the participants to the photographs was carried out using the SPSS-23.0 package program on the computer. Testing the distribution of normality first led to the preference for predictive statistics. The Kolmogorov-Smirnov Z normality test, which was applied to the scores on the face recognition tasks of participants with LD and the participants with ASD, revealed that the distribution was not normal $(\mathrm{p}<.05)$. The nonparametric Mann Whitney-U test, which is used for dichotomous independent variables, was used to determine whether there was any difference in dependent variables based on independent variables in non-normal distributions.

Descriptive statistics including frequencies (f), percentages (\%) and arithmetic means were used. Moreover, written records of the responses to the questions asked to the participants to reveal their clues to recognize the feelings were analyzed. The similarities and differences in the emotional processing patterns of the children in the two diagnostic groups were examined using the inductive analysis method, one of qualitative analysis methods.

\subsection{Interrater Reliability}

The answers of the following questions directed at the children to determine how and where they look and what clues they use to distinguish emotions were analyzed by a second researcher: "Of which part of the face/body did you look at to get this expression? What were the things/tips to help you find the answer?" A randomly chosen portion of $40 \%$ was also analyzed by the first researcher. The reliability of the study was found to be $96 \%$ in the calculation using the reliability formula of Miles and Huberman (1994).

\section{Findings}

\subsection{Quantitative Findings}

To determine if children with LD differ from children with ASD in terms of recognizing emotions from faces, scores of 300slides were examined separately by using the Mann Whitney- $U$ test. For the first set $U=817, p=.294$; for the 
second set $\mathrm{U}=818, \mathrm{p}=.831$ and for the third set $\mathrm{U}=83, \mathrm{p}=.943$ ). In other words, it was seen that the children diagnosed with LD did not differ from the children diagnosed with ASD in terms of face recognition.

The non-parametric Mann Whitney-U test was used to determine whether there was any difference between children's total scores of the body-language slide sets, and no significant difference was found between the scores of the diagnostic groups. For the first slide set $\mathrm{U}=792, \mathrm{p}=.661$; for the second set $\mathrm{U}=682.5, \mathrm{p}=.135$ and for the third set $\mathrm{U}=790, \mathrm{p}=.641$. Findings obtained from the slides used in the study show that children with LD did not differ from children with ASD in recognizing face and body language.

Table 2. The Result of the Non-Parametric Mann Whitney-U Test Conducted to Determine Whether there Was a Difference by Gender between the Total Scores of the Children with LD and ASD from the Face and Body Slide Sets

\begin{tabular}{ccccccc}
\hline & Gender & $\mathrm{n}$ & Mean rank & Total rank & $\mathrm{U}$ & $\mathrm{p}$ \\
\cline { 2 - 7 } & Male & 63 & 41.60 & 2620.50 & 592.500 & .941 \\
1st Face slide & Female & 19 & 41.18 & 782.50 & & \\
(2 Options) & Male & 63 & 41.35 & 2605.00 & 589.000 & .583 \\
2nd Face slide & Female & 19 & 42.00 & 798.00 & & \\
(4 Basic Emotions) & Male & 63 & 42.20 & 2658.50 & 554.500 & .622 \\
3rd Face slide & Female & 19 & 39.18 & 744.50 & & \\
(Without clues) & Male & 63 & 40.99 & 2582.50 & 566.500 & .721 \\
1st Body slide & Female & 19 & 43.18 & 820.50 & & \\
(Female) & Male & 63 & 40.37 & 2543.00 & 527.000 & .418 \\
2nd Body slide & Female & 19 & 45.26 & 860.00 & & \\
(Child) & Male & 63 & 40.90 & 2577.00 & 561.000 & .670 \\
3rd Body slide & Female & 19 & 43.47 & 826.00 & & \\
(Drawing) & & & & & &
\end{tabular}

As seen in Table 2, no significant difference was found between the scores of the face and body slides according to gender. Nevertheless, when we looked at the mean scores, it was seen that girls scored better than boys.

Table 3. The Result of the Non-Parametric Kruskal Wallis-H Test Conducted to Determine Whether There Was a Difference by Age between the Total Scores of the Children with LD and ASD from the Face and Body Slide Sets

\begin{tabular}{lcccccc}
\hline \multirow{5}{*}{ Face1 } & Age groups & $\mathrm{N}$ & $\overline{\mathrm{x}}$ & SD & KW & $\mathrm{p}$ \\
\cline { 2 - 7 } & Age 7-10 & 45 & 8.98 & 1.033 & .815 & .665 \\
& Age 11-14 & 31 & 12.13 & .922 & & \\
& Age 15-19 & 6 & 16.67 & 1.366 & & .439 \\
Face2 & Age 7-10 & 45 & 8.98 & 1.033 & 1.645 & \\
& Age 11-14 & 31 & 12.13 & .922 & & .433 \\
& Age 15-19 & 6 & 16.67 & 1.366 & & \\
Face3 & Age 7-10 & 45 & 8.98 & 1.033 & 1.676 & .777 \\
& Age 11-14 & 31 & 12.13 & .922 & & \\
& Age 15-19 & 6 & 16.67 & 1.366 & & \\
Body1 & Age 7-10 & 45 & 8.98 & 1.033 & .504 & \\
& Age 11-14 & 31 & 12.13 & .922 & & \\
& Age 15-19 & 6 & 16.67 & 1.366 & & \\
Body2 & Age 7-10 & 45 & 8.98 & 1.033 & 6.228 & \\
& Age 11-14 & 31 & 12.13 & .922 & & \\
& Age 15-19 & 6 & 16.67 & 1.366 & & \\
Body3 & Age 1-10 & 45 & 8.98 & 1.033 & 2.390 & \\
& Age 15-19 & 31 & 12.13 & .922 & & \\
\hline
\end{tabular}

As seen in Table 3, there was a significant difference between the age distributions of the groups and the scores they got from the 2 nd body slide. There was no significant difference between the age distributions of the groups and the 
scores they got from the other body and face slides. According to findings, it is possible to say that the change of the age groups of the children has no effect on the total scores they received from recognizing emotions through the face.

\subsection{Qualitative Findings}

In this section, we first provide graphs of the percentage of correct answers given by the children based on the face and body language slide sets, and then the inductive analyzes of the answers to the photos showed to identify the clues they used when responding.

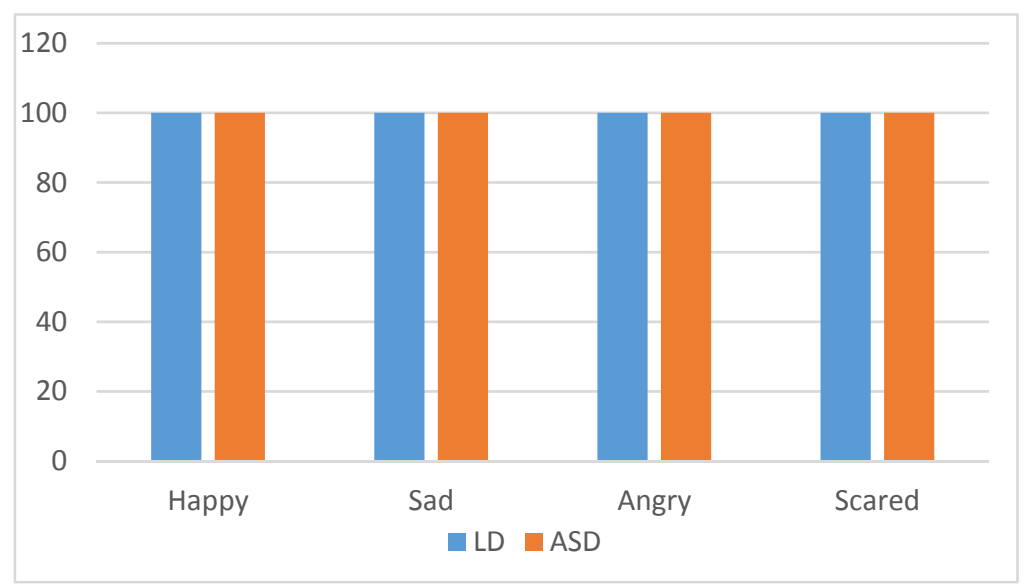

Figure 1. Participants' Percentage of Correctly Understanding Emotional Expressions from the 1st Face Slide (4 Photos)

Both groups were found to complete the face test on four photos in the same frame without making any mistakes $(100 \%)$.

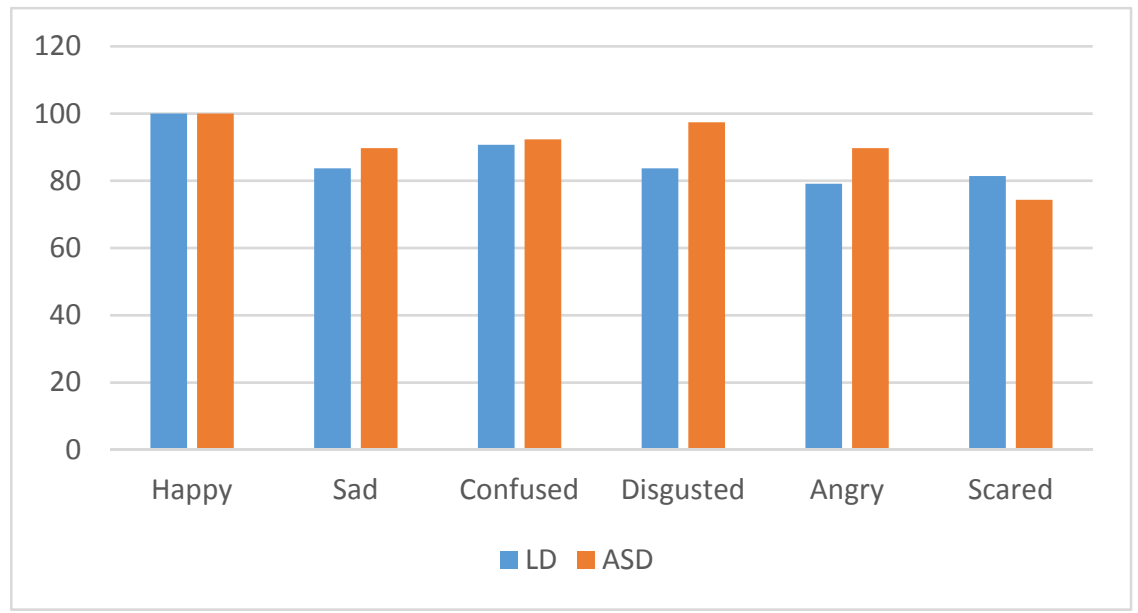

Figure 2. Participants' Percentages of Correctly Recognizing Emotional Expressions from the 2nd Face Slide Set (Photographs with 2 Options)

Both groups answered the happiness emotion without any mistakes (100\%). The second best identified emotion was the disgusted expression with $97.4 \%$ in the ASD group and the confused expression with $90.7 \%$ in the LD group. In general, the children with LD scored worse than the children with ASD. 


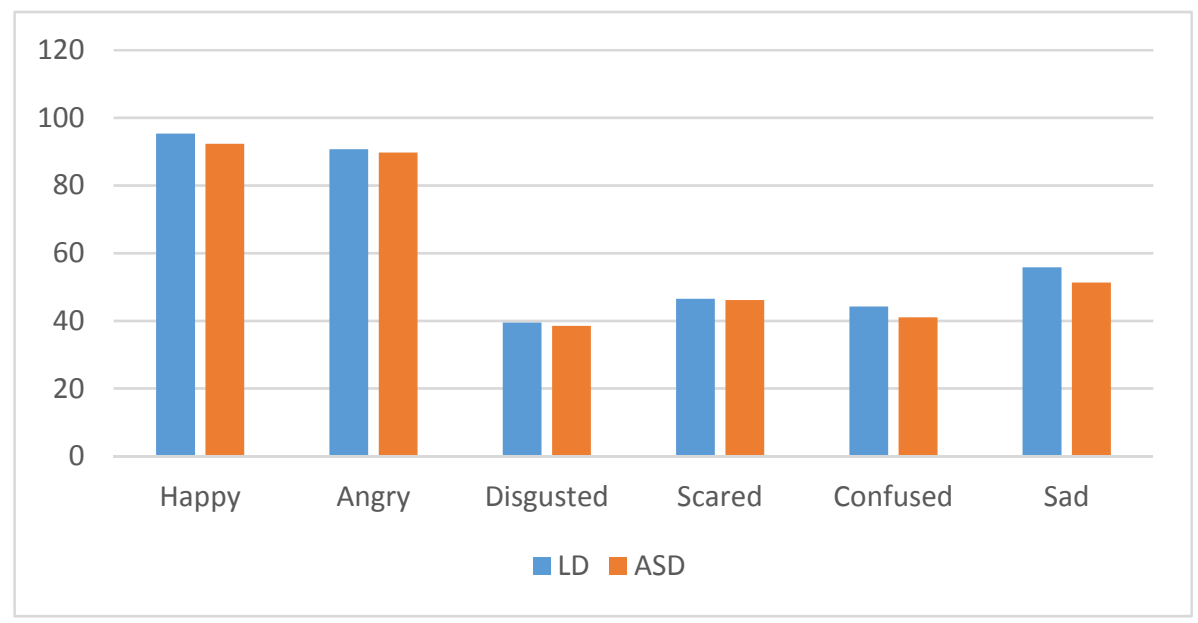

Figure 3. Participants' Percentage of Correct Understanding of Emotional Expressions from the 3rd Face Slide Set (without clues)

Happiness was the best identified emotion in both groups. The second best identified emotion was the angry expression with $89.7 \%$ in the ASD group and $90.7 \%$ in the LD group. The worst identified emotion was the disgusted expression with $38.5 \%$ in the ASD group and 39.5\% in the LD group. In the 3rd Face slide set without any clues offered, it was seen that children with LD gave more correct answers in naming the emotions than the autistic children did.

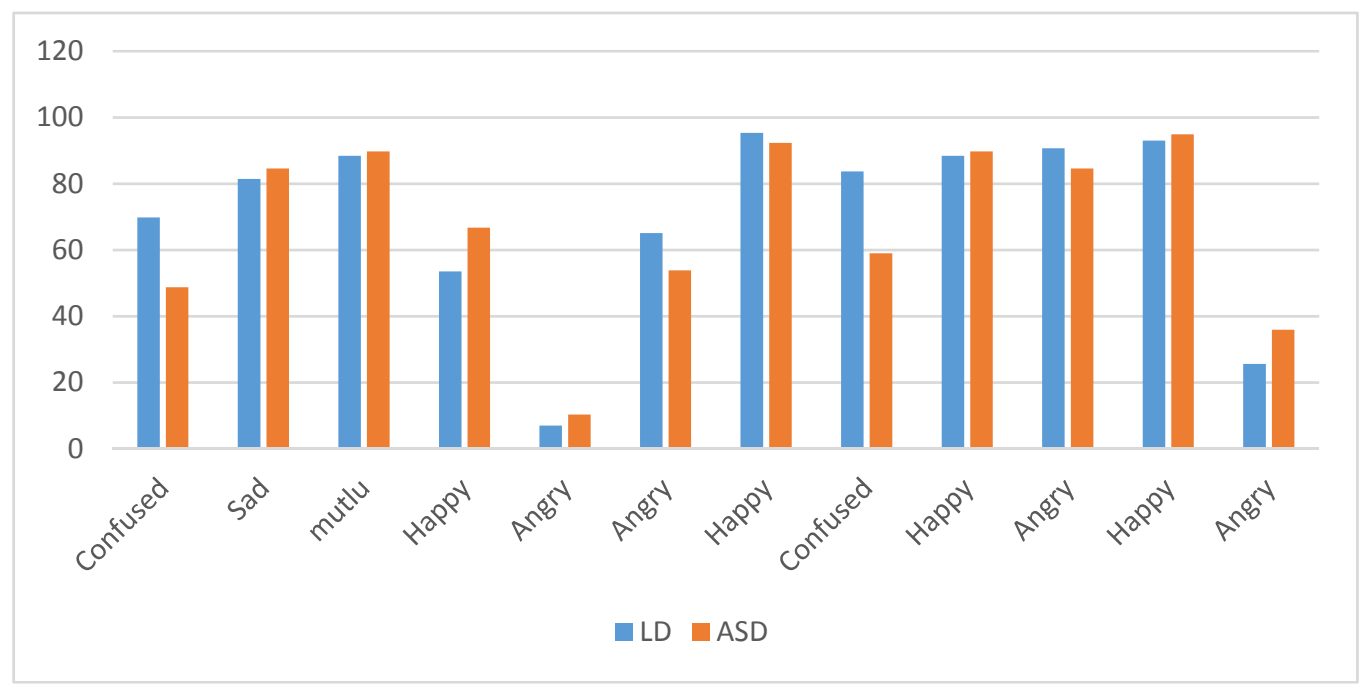

Figure 4. Participants' Percentage of Correctly Recognizing Emotional Expressions from the 1st Body Language Slide Set (photographs of females)

The best identified emotion was the happiness expression in both groups. It was seen that the expression of emotion which was the most difficult for both groups on the 1st Body slide was anger. 


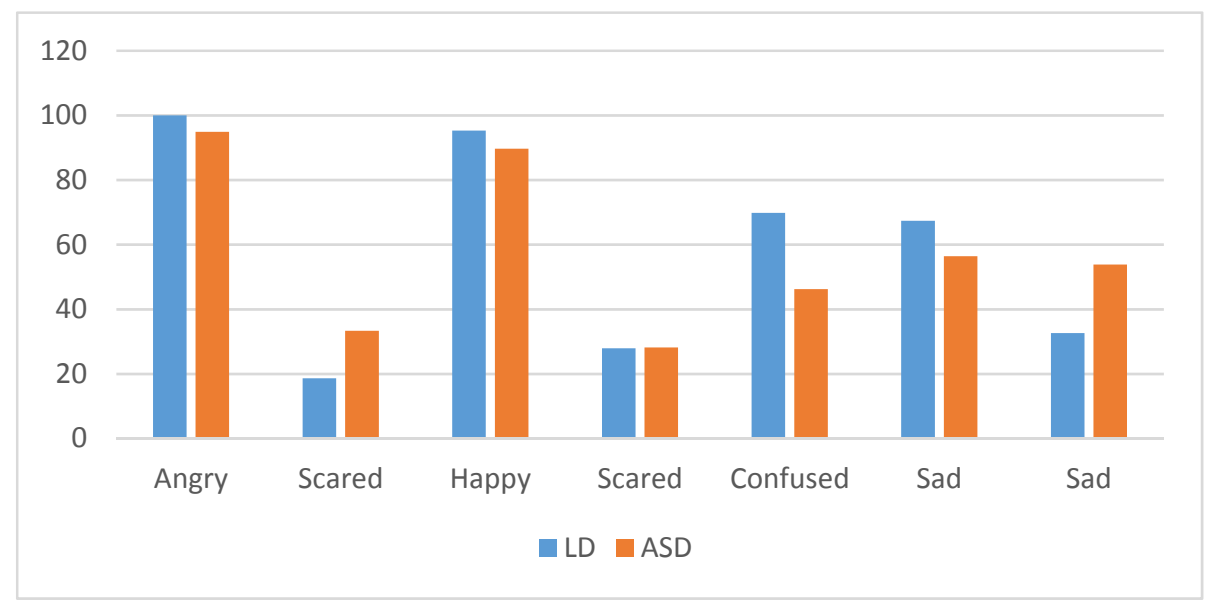

Figure 5. Participants' Percentage of Correctly Recognizing Emotional Expressions from the 2nd Body Language Slide Set (photographs of children)

Angry was the best identified emotion in both groups. The second best identified emotion was the happiness expression with $89.7 \%$ in the ASD group and $95.3 \%$ in the LD group.

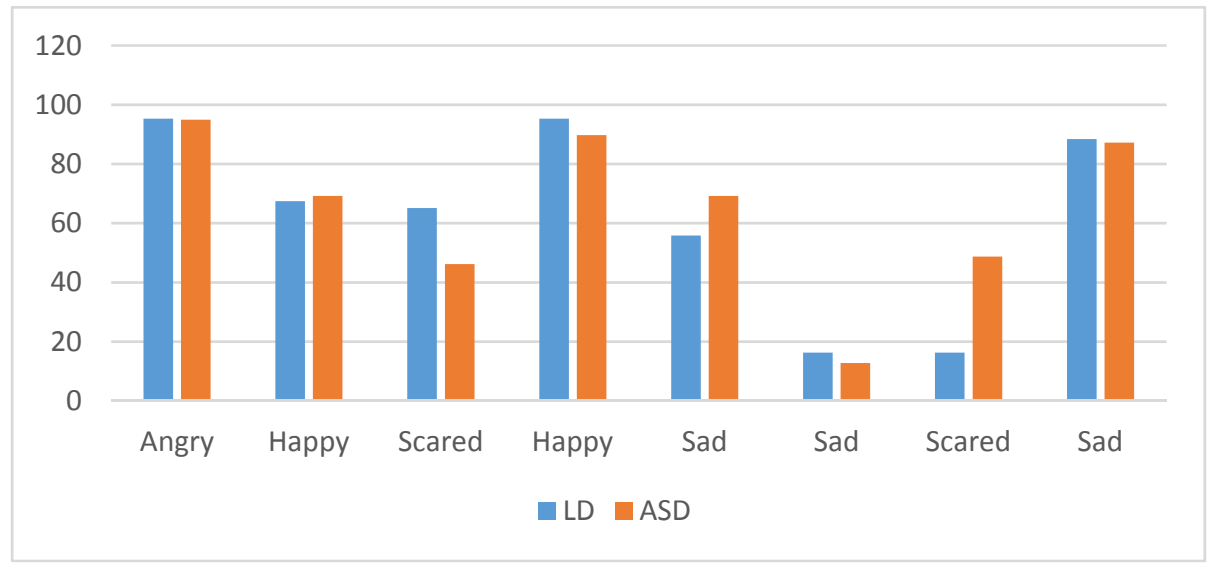

Figure 6. Participants' Percentage of Correctly Recognizing Emotional Expressions from the 3rd Body Language Slide Set (drawing photographs)

Percentage of accuracy of emotions varies according to clues in the photos. For the sad expression in the 5th photo, the LD group had 55.8\%, the ASD group had 69.2\%; For the sad expression in the 6th photo, the LD group had $16.3 \%$, the ASD group had $12.8 \%$; For the sad expression in the 8 th photo, the LD group had $88.4 \%$, the ASD group had $87.2 \%$.

\subsection{Findings Related to the Regions Where Children Refer to When Describing Emotions}

In terms of responses to sets of photographs, happiness was the feeling with the most correct answers in both groups. In combined sets of body and facial expressions, both groups were had difficulties, and their correct answers declined.

\subsection{Qualitative Findings for Face-Based and Body-Based Clues}

On each slide, the children were asked of which part of the face/body they looked at when identifying the emotion, and the responses were recorded by the researcher. Some students did not give any explanations when responding. Responses given to face slides were categorized under three groups as "looking at the whole face", "looking at the mouth region" and "looking at the eyes region." In addition to these three groups, "looking at the hands and arms" was added to the answers given to the body language slides. And the frequencies and percentages of their responses were compared in four groups. Since the answers given by the students were calculated for each of the images in the 
slides, the frequencies presented in the tables were greater than the number of children.

Table 4. Face-Based Clues Used by the Participants

\begin{tabular}{|c|c|c|c|c|c|c|c|c|c|c|c|c|}
\hline & \multicolumn{6}{|c|}{ Children with LD } & \multicolumn{6}{|c|}{ Children with ASD } \\
\hline & \multicolumn{2}{|c|}{ FACE1 } & \multicolumn{2}{|c|}{ FACE2 } & \multicolumn{2}{|c|}{ FACE3 } & \multicolumn{2}{|c|}{ FACE1 } & \multicolumn{2}{|c|}{ FACE2 } & \multicolumn{2}{|c|}{ FACE3 } \\
\hline & $\mathrm{f}$ & $\%$ & $\mathrm{f}$ & $\%$ & $\mathrm{f}$ & $\%$ & $\mathrm{f}$ & $\%$ & $f$ & $\%$ & $\mathrm{f}$ & $\%$ \\
\hline The whole of the face & 94 & 36.43 & 187 & 54.36 & 109 & 42.24 & 53 & 22.64 & 58 & 18.58 & 46 & 19.65 \\
\hline Mouth region & 75 & 29.6 & 88 & 25.57 & 72 & 27.89 & 145 & 61.95 & 146 & 46.79 & 152 & 64.95 \\
\hline Eye region & 89 & 34.49 & 69 & 20.05 & 76 & 29.44 & 36 & 15.37 & 108 & 34.6 & 36 & 15.37 \\
\hline
\end{tabular}

According to the findings obtained from face recognition slides, the children with LD generally focused on the whole face $(\mathrm{Y} 1=36.43 \%, \mathrm{Y} 2=54.36 \%, \mathrm{Y} 3=42.24 \%)$ and then the eye region to make sense of emotions, while the children with ASD focused on the mouth region ( $\mathrm{Y} 1=61.95 \%, \mathrm{Y} 2=46.79 \%, \mathrm{Y} 3=64.95 \%)$.

Table 5. Body-based Clues Used by the Participants

\begin{tabular}{lcccccccccccc}
\hline & \multicolumn{4}{c}{ Children with LD } & \multicolumn{4}{c}{ Children with ASD } \\
& BODY & \multicolumn{1}{c}{ BOD2 } & \multicolumn{1}{c}{ BODY } & \multicolumn{1}{c}{ BODY } & \multicolumn{2}{c}{ BODY2 } & BODY3 \\
\hline & $\mathrm{f}$ & $\%$ & $\mathrm{f}$ & $\%$ & $\mathrm{f}$ & $\%$ & $\mathrm{f}$ & $\%$ & $\mathrm{f}$ & $\%$ & $\mathrm{f}$ & $\%$ \\
\hline The whole body & 216 & 44.08 & 240 & 50 & 204 & 52.30 & 142 & 28.97 & 80 & 18.01 & 121 & 31.02 \\
Mouth region & 72 & 14.84 & 45 & 9.36 & 35 & 8.97 & 276 & 56.31 & 241 & 54.26 & 207 & 53.06 \\
Eye region & 157 & 32.03 & 168 & 33.53 & 111 & 14.87 & 48 & 9.78 & 78 & 17.56 & 30 & 7.68 \\
Arms and hands & 45 & 9.18 & 27 & 7.07 & 21 & 5.38 & 24 & 4.89 & 32 & 10.12 & 32 & 8.19 \\
\hline
\end{tabular}

Findings from the body slides also showed that children with LD focused more on the whole body $(\mathrm{B} 1=44.8 \%$, $\mathrm{B} 2=50 \%, \mathrm{~B} 3=52.30 \%)$ while the children with ASD focused on the mouth region $(\mathrm{B} 1=56.31 \%, \mathrm{~B} 2=54.26 \%$, $\mathrm{B} 3=53.06 \%$ ) when deciding on emotions.

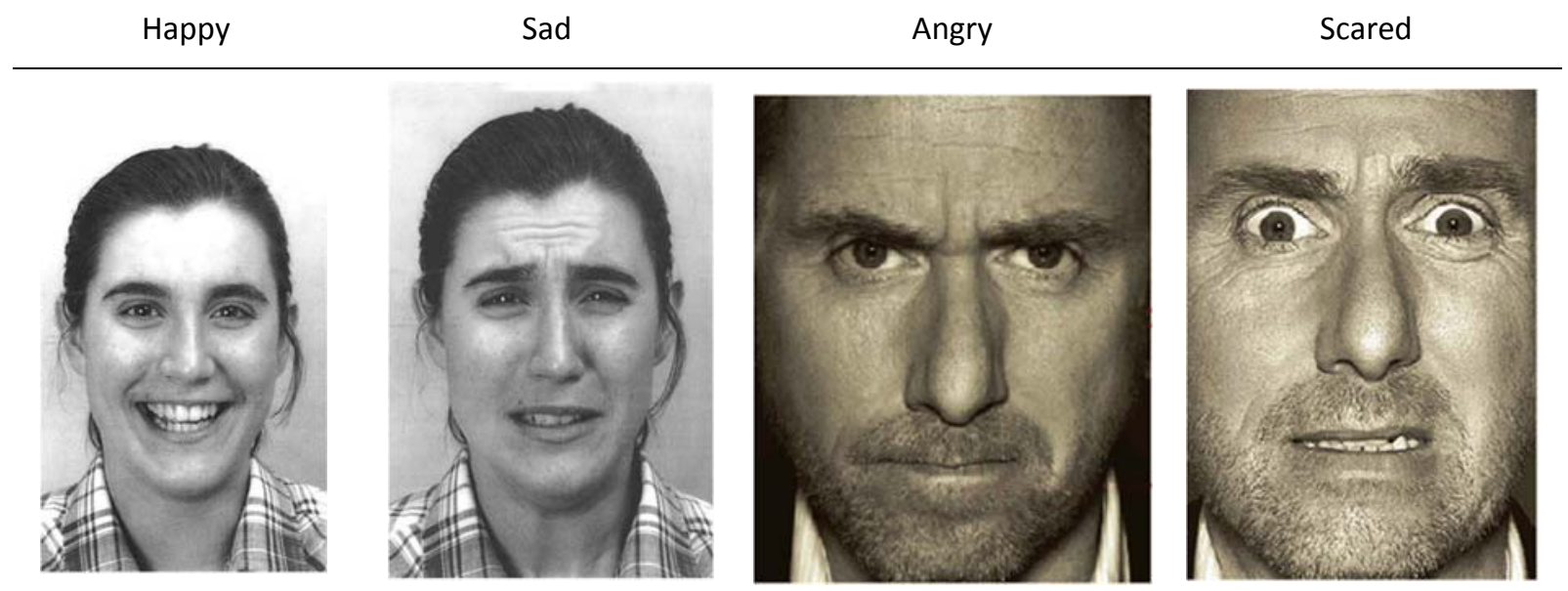

Figure 7. Sample Photos from Face Slides

Children with LD usually gave explanations, such as the following, regarding the whole face that was presented to them on the face slides.

Happy

"she laughs by showing her teeth, her cheeks went up, her skin was wrinkled around her eyes"

$\mathrm{Sad}$

"inner corners of her eyebrows raised, her forehead was wrinkled, her lips were shrunk"

Angry 
"he squeezed his lips, his eyes were widened, his cheeks were swollen"

Scared

"his lips were spaced, his cheeks were stretched, his eyes were bulged"

Children with ASD usually gave explanations, such as the following, regarding the mouth region that was presented to them on the face slides.

Happy

"she is laughing with her teeth clearly seen"

$\mathrm{Sad}$

"she made reverse laughing sign with her lips"

Angry

"he leaned his mouth to each side"

Scared

"he clenched his teeth, his lips stretched"

Happy Scared Angry Disgusted Confused

Figure 8. Sample Photos from Body Slides

Children with LD usually gave explanations, such as the following, regarding the whole face that was presented to them on the body slides.

Happy

"Her mouth was like giggling; her eyes were squinting because of laughing"

"she gave a side pose; she had a smile on her face"

"she opened her hands like saying hello; she was laughing with her teeth visible"

$\mathrm{Sad}$

"he supported his head with his hands and he lost focus in his eyes, He pulled down of lip corners slightly"

Scared

"he opened his eyes and mouth, he wrapped his body with his arms"

Angry

"she squinted one of her eyes; she clenched her teeth; she was rubbing her hands together"

"her cheeks were inflated; she scowled; her lips were shrunk"

Disgusted

"she was squeezing her nose with her hand; she pulled out her tongue; she turned her head"

Confused

"she attached her arms to her body; she opened her eyes; she withdrew her head"

"she took her hands to her mouth; she opened her eyes"

Children with ASD usually gave explanations, such as the following, regarding the mouth region that was presented 
to them on the body slides.

Happy

"she is laughing and showing her teeth"

"she is smiling while being photographed"

"she is laughing by showing his teeth"

Sad

"he lowered her mouth down"

"he got weak because of unhappiness"

"he is sad so he supported his chin to his arms"

Scared

"his mouth was warped"

Angry

"she was so angry thats he has tightened his teeth too much"

"she is rubbing his hands because of anger"

Disgusted

"she pulled out her tongue"

Confused

"she closed her mouth, she couldn't breathe"

"she opened her mouth like "O" and covered that with her hands"

To sum up, the children with ASD stated that they recognized the emotions of the character in both face and body language illustrations by looking at the mouths of people more. The children with LD expressed that they looked at the whole picture and eyes more.

Table 6. Chi-Square Test Results on Participants' Use of Face-Based Clues

\begin{tabular}{lcccccc}
\hline Slides & Region & \multicolumn{2}{c}{ Groups } & \multirow{2}{*}{$X^{2}$} & SD & p \\
& The Whole of the Face & 187 & 58 & 89.544 & 2 & .000 \\
Face1 & Mouth Region & 88 & 146 & & & \\
& Eye Region & 69 & 108 & & & .000 \\
& The Whole of the Face & 94 & 53 & 55.141 & 2 & .000 \\
Face2 & Mouth Region & 75 & 145 & & & \\
& Eye Region & 89 & 36 & & & \\
Face3 & The Whole of the Face & 109 & 46 & 67.534 & & \\
\hline
\end{tabular}

According to the results of Pearson's Chi-square statistics, when the groups were examined separately for the slides of face 1 , face 2 , and face 3 , all $\mathrm{p}$ values were less than 0.05 , so it was seen that there was a significant difference between the regions to which the children with LD and the ASD referred in terms of recognition of emotions from the face. 
Table 7. Chi-Square Test Results on Participants' Use of Body-Based Clues

\begin{tabular}{|c|c|c|c|c|c|c|}
\hline \multirow[t]{2}{*}{ Slides } & \multirow[t]{2}{*}{ Region } & \multicolumn{2}{|c|}{ Groups } & \multirow[t]{2}{*}{$X^{2}$} & \multirow[t]{2}{*}{ SD } & \multirow[t]{2}{*}{$\mathrm{p}$} \\
\hline & & LD & ASD & & & \\
\hline \multirow{4}{*}{ Body1 } & $\begin{array}{l}\text { The Whole of the } \\
\text { Body }\end{array}$ & 216 & 142 & 199.230 & 3 & .000 \\
\hline & Mouth Region & 72 & 276 & & & \\
\hline & Eye Region & 157 & 48 & & & \\
\hline & Arms and hands & 45 & 24 & & & \\
\hline \multirow{5}{*}{ Body 2} & $\begin{array}{l}\text { The Whole of the } \\
\text { Body }\end{array}$ & 240 & 80 & 245.748 & 3 & .000 \\
\hline & Mouth Region & 45 & 241 & & & \\
\hline & Eye Region & 168 & 78 & & & \\
\hline & Arms and hands & 27 & 32 & & & \\
\hline & $\begin{array}{l}\text { The Whole of the } \\
\text { Body }\end{array}$ & 204 & 121 & 191.905 & 3 & .000 \\
\hline \multirow{3}{*}{ Body3 } & Mouth Region & 35 & 207 & & & \\
\hline & Eye Region & 111 & 30 & & & \\
\hline & Arms and hands & 21 & 32 & & & \\
\hline
\end{tabular}

According to the results of the Pearson's Chi-square statistic, when the groups were examined separately for the slides of body1, body 2 and body 3 , all $p$ values were less than 0.05 and therefore there was a significant relationship between the children's recognition of emotions: children with LD looked at the entire body when they identified the emotions, and children with ASD looked at the mouth area.

\section{Discussion}

In this study, children with LD and children with ASD were compared in terms of skills of recognizing emotions from facial expressions and body language. In previous studies, children with LD were compared with their ND peers in terms of the time it takes to understand, recognize, and name emotions. Despite the fact that both groups are known to have problems in the social context, there is no research comparing the two groups in terms of recognizing emotions (Noens \& van Berckelaer-Onnes, 2004; Kavale \& Mostert, 2004; Klin et al., 1995; Knott et al. 1995; Gresham, 1992).

The findings of the study show that there is no statistically significant difference in recognizing emotions between children with LD and children with ASD. These findings can serve as indicators of the complexity of the interrelationships observed between autism and learning disability. The severity of autistic symptomatology varies according to the level of learning disability. Conversely, some children with LD display autistic features without fulfilling the criteria necessary for a diagnosis of autism (Gillberg \& Billstedt, 2000; Gillberg \& Coleman, 2000). Although there was no statistically significant difference in recognizing emotions between the two groups, children with LD were able to better recognize the cues identifying emotions, but not to correctly name them. As the cues presented in the slides were removed, the percentage of children responding correctly declined. Additionally, when the cues were removed, there was an almost half-way reduction particularly in naming the emotions such as disgusted, scared and confused. The problems of children with LD in correctly interpreting the cues on the face make it difficult for them to distinguish emotions from one another (Holder \& Kirkpatrick, 1991; Bryan, 1977).

Happiness was a more easily distinguishable emotion than all other emotions on all slides. The most correct answers were given in the face expressions slides. It was observed that happiness was the fastest emotion to name in this area and that the rates of confusion with other emotions were very low. This finding is consistent with the results of similar studies reported in the literature (Kılıç-Tülü \& Ergül, 2016; Bauminger et al., 2005; Dimitrovsky, 1998; Holder \& Kirkpatrick, 1991). Especially in the expression of happiness, the fact that the mouth area is upwards in shape and that children with OSD usually focused on the mouth region to describe emotions make it easier to distinguish them from other emotions. As a matter of fact, Arı and Şahin (2004) stated that children focus on the mouth region in the expression of happiness. In addition, this result may be related to the profusion of the experiences children have with happiness. Research shows that children begin to recognize happiness from their infancy through their mothers' face expressions and that they can clearly distinguish happiness in face expressions from other emotions from the age of 2-3 (Arı \& Şahin, 2004; Arı, Bayhan, Üstün, Akman, Şahin, 1995; Gross \& 
Ballif, 1991).

Both groups had trouble in recognizing more negative feelings, such as confused, scared, and angry. In many studies, individuals with ASD were found to have problems in defining negative feelings such as fear (Pelphrey et al., 2002), anger (Giola \& Brosgole, 1988) and disgust (Golan, Baron-Cohen, \& Hill, 2006). Children with LD can experience inadequacies in the field of social cognition and social skills (Girli, 2013; Guralnick, Hammond, \& Connor, 2003). This prevents them from understanding facial expressions such as happiness, sadness, and complex emotions such as thoughtful, bored, and body language, and that this leads them to be unable to read social cues (Vaughn \& Grecea, 1993).

Law Smith, Montagne, Perrett, Gill and Gallagher (2010) noted that the intensity of emotions in tasks/duties used could also affect outcomes. In this study, children were also able to define emotions more easily in photographs where emotions were intensely and clearly expressed. In a similar study, comparable results were observed in the age group of 7 to 12 years. For example, $100 \%$ of the children with LD and $82.45 \%$ of the children with ASD responded correctly in the emotion of "anger" and in photographs with clearer hints and sharper expressions such as "the eyebrows being frowned, the teeth being clenched" (Girli, 2016).

In this study, the children with LD usually looked at the whole photo, while the children with autism focused especially around the mouth to describe feelings. Some studies suggest that autistic children look shorter and less frequently at the eye region than those without autistic diagnosis (Dalton et al., 2005; Pelphrey et al., 2002). Moreover, there are studies showing that autistic children cannot use the information on the upper face area as effectively as normally developed children in distinguishing the expressions (Spezio et al., 2007; Gross, 2004; Baron-Cohen et al., 1997). As in this study, there are also studies that show that children with autism are more likely to focus on the mouth region and use the information in this region to make assessments (Spezio et al., 2007; Neumann, Spezio, Piven, Adolphs, 2006; Pelphrey et al., 2002).

In this study, it was found that gender did not make a significant difference in recognition of emotions in the both groups of diagnosis. Despite the fact that the understanding of emotions differs according to gender in the literature by and large, there are also studies indicating that children's ability to understand emotions does not differ according to their gender (Karayılmaz, 2008; Marten \& Green, 2005; Schultz et al., 2001). Naming emotions is an important part of understanding emotions. It has been pointed out in previous studies that the naming and recognition of emotional facial expressions of older children is in harmony, but it is more difficult to name emotions for children of young age (Russell \& Widen, 2010; Nelson \& Russell, 2014). In this study, children were grouped by age groups and examined for differences. The results showed that there was no statistically significant difference in terms of recognition of emotions, but it was observed that the scores increased as the age increased. Briefly, no significant difference could be found between the children with LD and the children with ASD, in terms of recognizing emotions from the face and body.

\section{Limitations and Suggestions}

There are some limitations to be considered when assessing the results obtained in this study. The first of them is that complex emotions such as arrogance, shame, pride and loneliness were not included in this study. Children with LD are thought to be able to experience more difficulties in recognizing these emotions. For this reason, it is considered that the processes of recognition of such feelings can be examined in detail by using social stories as well as photographs in future research. Secondly, the effects of these problems on their social skills and friendship have not been examined. Therefore, it is thought that it is important to examine the social consequences of children's recognition skills. It is suggested that in future studies, children should be assessed for their ability to recognize emotions using a broader sample and using social events involving facial expressions by working with different subgroups of learning disability (dyslexia, dysgraphia, dyscalculia). Finally, a limited age group and demographic characteristics were included in the study. When similar studies are carried out, it is suggested that variables such as different age groups, parental education level, characteristics related to home and class environment, interaction environments, experiences, teacher competencies, support processes can be added and their effects on these skills can be examined.

\section{References}

American Psychiatric Association. (1994). Diagnostic and statistical manual of mental disorders (4th ed.). Washington, DC: Author. 
Arı, R., \& Seçer Şahin, Z. (2004). The ability to recognize emotional facial expressions of children in the preschool period is examined in terms of various variables. Selcuk University. Journal of Social Sciences Institute, 11, 67-84.

Arı, M., Bayhan, P., Üstün, E., Akman, B., \& Şahin, S. (1995). Examination of children's emotional expressions and their perceptions by age and sex between 48-72 months. Child and Youth Mental Health Magazine, 2(3), 119-125.

Arthur, A. R. (2003). The emotional lives of people with learning disability. British Journal of Learning Disabilities, 31(1), 25-30. https://doi.org/10.1046/j.1468-3156.2003.00193.x

Attwood, T. (2000). Strategies for improving the social integration of children with Asperger's syndrome. Autism, 4, 85-100. https://doi.org/10.1177/1362361300004001006

Baron-Cohen, S., Jollife, T., Martimore, C., \& Robertson, M. (1997). Another advanced test of theory of mind: evidence from very high functioning adults with autism or Asperger syndrome. Journal of Child Psychology and Psychiatry, 38, 813-822. https://doi.org/10.1111/j.1469-7610.1997.tb01599.x

Bauminger, N., Edelsztein, H. S., \& Morash, J. (2005). Social information processing and emotional understanding in children with LD. Journal of Learning Disabilities, 38, 45-61. https://doi.org/10.1177/00222194050380010401

Baron-Cohen, S. (1995). The eye direction detector (EDD) and the shared attention mechanism (SAM): Two cases for evolutionary psychology. In Portions of this paper were presented at the Society for Research in Child Development Conference, New Orleans, Mar 1993; the British Psychological Society, Welsh Branch," Faces" Conference, U Wales Coll of Cardiff, Sep 1993; and the British Society for the Philosophy of Science" Roots of Joint Reference" Conference, U Bristol, Nov 1993. Lawrence Erlbaum Associates, Inc.

Bender, W. N. (2008). Learning disabilities: Characteristics, identification, and teaching strategies (6th ed.). Boston: Pearson Education.

Bloom, E., \& Heath, N. (2010). Recognition, expression, and understanding facial expressions of emotion in adolescents with nonverbal and general learning disabilities. Journal of Learning Disabilities, 43(2), 180-192.

Bryan, T. (1977). Learning disabled children's comprehension of nonverbal communication. Journal of Learning Disabilities, 10, 36-41. https://doi.org/10.1177/002221947701000808

Bursuck, W. (1989). A comparison of students with learning disabilities to low achieving and higher achieving students on three dimensions of social competence. Journal of Learning Disabilities, 22(3), 188-194. https://doi.org/10.1177/002221948902200310

Büyüköztürk, Ş., Çakmak, E. K., Akgün, Ö. E., Karadeniz, Ş., \& Demirel, F. (2010). Scientific Research Methods. Ankara: Pegem Akademi Publisher.

Büyüköztürk, Ş. (2017). Manual of Data Analysis For Social Sciences. Pegem Atı İndeksi, 1, 213.

Crick, N. R., \& Dodge, K. A. (1994). A review and reformulation of social informationprocessing mechanisms in children's social adjustment. Psychological Bulletin, 115, 74-101. https://doi.org/1994-20990-001

Dailey MN., Cottrell GW., Padgett C., \& Adolphs R. (2002). EMPATH: a neural network that categorizes facial expressions. J Cogn Neurosci, 14, 1158-1173. https://doi.org/10.1162/089892902760807177

Dalton, K. M., Nacewicz, B. M., Johnstone, T., Schaefer, H. S., Gernsbacher, M. A., Goldsmith, H. H., Alexander, A. L., \& Davidson, R. J. (2005). Gaze fixation and the neural circuitry of face processing in autism. Nature Neuroscience, 8(4), 519- 526. https://doi.org/10.1038/nn1421

Dimitrovsky, L., Spector, H., Levy-Shiff, R., \& Vakil, E. (1998). Interpretation of facial expressions of affect in children with learning disabilities with verbal or nonverbal deficits. Journal of Learning Disabilities, 31(3), 286-292. https://doi.org/10.1177/002221949803100308

Dimitrovsky, L., Spector, H., \& Levy-Shiff, R. (2000). Stimulus gender and emotional difficulty level: Their effect on recognition of facial expressions of affect in children with and without LD. Journal of Learning Disabilities, 33(5), 410-416. https://doi.org/10.1177/002221940003300501

Doğmaz, S., \& Girli, A. (2017). The Relationship Between Learning Disability and Theory Of Mind. Journal of International Social Research, 10(51). https://doi.org/10.1155/2012/490647

Elias, M. J. (2004). The connection between social-emotional learning and learning disabilities: Implications for 
intervention. Learning Disability Quarterly, 27(1), 53-63. https://doi.org/10.2307/1593632

Ekman, P. (1999). Basic emotions. In T Dagleish, M Power (Eds.), Handbook of Cognition and Emotion, 45-60. Chichester, Wiley.

Flavell, J. H. (2004). Theory-of-mind development: Retrospect and prospect. Merrill Palmer Quarterly, 50(3), 274-290. https://doi.org/10.1353/mpq.2004.0018

Ghazıuddın, M. (2000). Autism in Mental Retardation. Current Opinion in Psychiatry, 13, 481-4.

Girli, A., \& Sabirsiz, S. (2011). The Examination of the Effectiveness of the Instructional Program that Teaches Emotions through Pictures to Children with Autism. Ankara University Faculty of Educational Sciences Journal of Special Education, 12(01), 1-16.

Girli, A. (2013). An examination of the relationships between the social skill levels, self concepts and aggressive behavior of students with special needs in the process of inclusion education. Çukurova University. Faculty of Education Journal, 42(1), 23.

Girli, A. (2016). Examining sensory differences of children with autism in early childhood: Effects of school and home settings. Journal of Human Sciences, 13(1), 518-531. https://doi.org/10.14687/ijhs.v13i1.3520

Gillberg, C., \& Billstedt, E. (2000). Autism and Asperger Syndrome: Coexistence with Other Clinical Disorders. Acta Psychiatrica Scandinavica, 102, 321-30. https://doi.org/10.1034/j.1600-0447.2000.102005321.x

Gillberg, C., \& Coleman, M. (2000). The biology of the autistic syndromes. Cambridge University Press.

Grelotti DJ., Gauthier I., \& Schultz RT. (2002). Social interest and the development of cortical face specialization: what autism teaches us about face processing. Dev Psychobiol, 40, 213-225. https://doi.org/10.1002/dev.10028

Gresham, F. M. (1992). Social skills and learning disabilities: Causal, concomitant, or correlational?. School Psychology Review. https://doi.org/1993-10141-001

Gross, A. L., \& Ballif, B. (1991). Children's understanding of emotion from facial expressions and situations: A review. Developmental Review, 11, 368-398. https://doi.org/10.1016/0273-2297(91)90019-K

Gross, T. F. (2004). The perception of four basic emotions in human and nonhuman faces by children with autism and other developmental disabilities. Journal of Abnormal Child Psychology, 32(5), 469-480. https://doi.org/10.1023/B:JACP.0000037777.17698.01

Harms, M. B., Martin, A., \& Wallace, G. L. (2010). Facial emotion recognition in autism spectrum disorders: a review of behavioral and neuroimaging studies. Neuropsychology review, 20(3), 290-322. https://doi.org/10.1007/s11065-010-91386.

Holder, H. B., \& Kirkpatrick, S. W. (1991). Interpretation of emotion from facial expressions in children with and without learning disabilities. Journal of Learning Disabilities, 24, 170-177. https://doi.org/10.1177/002221949102400305

Karayllmaz, Duygu (2008). Investigation of the relation between the emotional quotient and social adaptation skills of the children going to pre-school classes. Published Master Thesis. Institute of Educational Sciences, Gazi University, Ankara

Kavale, K. A., \& Forness, S. T. (1996). Social skills deficits and LD: A meta-analysis. Journal of Learning Disabilities, 29, 226-237. https://doi.org/10.1177/002221949602900301

Kavale, K. A., \& Mostert, M. P. (2004). Social skills interventions for individuals with learning disabilities. Learning Disability Quarterly, 27(1), 31-43. https://doi.org/10.2307/1593630

Kılıç-Tülü, B., \& Ergül, C. (2016). Recognition of emotions in children with learning disabilities. Ankara University Faculty of Educational Sciences Journal of Special Education, 17(3), 207-229.

Klin, A., Volkmar, F. R., Sparrow, S. S., Cicchetti, D. V., \& Rourke, B. P. (1995). Validity and neuropsychological characterization of Asperger syndrome: Convergence with nonverbal learning disabilities syndrome. Journal of Child Psychology and Psychiatry, 36(7), 1127-1140. https://doi.org/10.1111/j.1469-7610.1995.tb01361.x

Knott, F., Lewis, C., \& Williams, T. (1995). Sibling interaction of children with learning disabilities: A comparison of autism and Down's syndrome. Journal of child psychology and psychiatry, 36(6), 965-976. https://doi.org/10.1111/j.1469-7610.1995.tb01343.x

Martin, R. M., \& Green, J. A. (2005). The use of Emotion explanations by mothers: Relation to preschoolers's 
gender and understanding of emotions. Social Development, 14(2), 229-249. https://doi.org/10.1111/j.1467-9507.2005.00300.x

Mckenzie, K., Matheson, E., Mckaskie, K., Hamilton, L., \& Murray, G. C. (2000). Impact of Group Training on Emotion Recognition in Individuals with Learning Disability. British Journal of Learning Disabilities, 28(4), 143-147. https://doi.org/10.1046/j.1468-3156.2000.00061.x

McKleskey, J., \& Pacchiano, D. (1994). Mainstreaming students with learning disabilities: Are we making progress? Exceptional Children, 60, 508-517. https://doi.org/10.1177/001440299406000604

McPartland, J. C., Webb, S. J., Keehn, B., \& Dawson, G. (2011). Patterns of visual attention to faces and objects in autism spectrum disorder. Journal of autism and developmental disorders, 41(2), 148-157. https://doi.org/10.1007/s10803-010-1033-8.

Meadan, H., \& Halle, J. W. (2004). Social perceptions of students with learning disabilities who differ in social status. Learning Disabilities Research and Practice, 19, 71-82. https://doi.org/10.1111/j.15405826.2004.00091.x

Most, T., \& Greenbank, A. (2000). Auditory, visual and auditory-visual perception of emotions by adolescents with and without learning disabilities, and their relationship to social skills. Learning Disabilities, Research and Practice, 5(4), 171-178. https://doi.org/10.1207/SLDRP1504_1

Nabuzoka, D., \& Smith, P. K. (1999). Distinguishing serious and plyful fighting by children with LD and nondisabled children. Journal of Child Psychology and Psychiatry, 40, 883-890. https://doi.org/10.1111/1469-7610.00506

Nelson, N. L., \& Russell, J. A. (2014). Dynamic facial expressions allow differentiation of displays intended to convey positive and hubristic pride. Emotion, 14(5), 857. https://doi.org/2014-21027-001

Neth, D., \& Martinez AM. (2010). A computational shape-based model of anger and sadness justifies a configural representation of faces. Vision Res, 50, 1693-1711. https://doi.org/10.1016/j.visres.2010.05.024

Neumann, D., Spezio, M. L., Piven, J., \& Adolphs, R. (2006). Looking you in the mouth: abnormal gaze in autism resulting from impaired top-down modulation of visual attention. Social Cognitive and Affect Neuroscience, 1, 194-202. https://doi.org/10.1093/scan/ns1030

Noens, I., \& van Berckelaer-Onnes, I. (2004). Making sense in a fragmentary world: Communication in people with autism and learning disability. Autism, 8(2), 197-218. https://doi.org/10.1177/1362361304042723

Nomi JS., Scherfeld D., Friederichs S., Schäfer R., Franz M., \& Wittsack HJ et al. (2008). On the neural networks of empathy: a principal component analysis of an fMRI study. Behav Brain Funct, 4, 41-54. https://doi.org/10.1186/1744-9081-4-41

Nowicki, S., \& Duke, M. P. (1992). The association of children's nonverbal decoding abilities with their popularity, locus of control, and academic achievement. The Journal of Genetic Psychology, 153, 385-393. https://doi.org/10.1080/00221325.1992.10753734

O'Brien, G., \& Pearson, J. (2004). Autism and learning disability. Autism, 8(2), 125-140. https://doi.org/10.1177/1362361304042718

Özen, K. (2011). Analysis of the relation between the theory of mind abilities developed by children of 7-9 ages diagnosed by special learning disabilities and their social development and its comparison with the healthy developed group. Published master thesis. Maltepe University, Social Sciences Institute, Istanbul.

Pelphrey, K. A., Sasson, N. J., Reznick, J. S., Paul, G., Goldman, B., \& Piven, J. (2002). Visual scanning of faces in autism. Journal of Autism and Developmental Disorders, 32(4), 249-261. https://doi.org/10.1023/A:1016374617369

Petti, V. L., Voelker, S. L., Share, D. L., \& Hayman-Abello, S. E. (2003). Perception of nonverbal emotion cues by children with nonverbal learning disabilities. Journal of Developmental and Physical Disabilities, 15, 23-36. https://doi.org/10.1023/A:1021400203453

Razza, R.A., \& Blair, C. (2009). Associations among false-belief understanding, executive function, and social competence: A longitudinal analysis. Journal of Applied Developmental Psychology, 30, 332-343. https://doi.org/10.1016/j.appdev.2008.12.020

Reiff, H. B., \& Gerber, P. J. (1990). Cognitive correlates of social perception in students with LD. Journal of 
Learning Disabilities, 23, 260-262. https://doi.org/10.1177/002221949002300410

Richell, R. A., Mitchell, D. G. V., Newman, C., Leonard, A., Baron-Cohen, S., \& Blair, R. J. R. (2003). Theory of mind and psychopathy: can psychopathic individuals read the 'language of the eyes'?. Neuropsychologia, 41(5), 523-526. https://doi.org/10.1016/s0028 3932(02)00175-6

Russell, J. A., \& Widen, S.C. (2010). Children's scripts for social emotions: Causes and consequences are more central than are facial expressions. British Journal of Developmental Psychology, 28(3), 565-581. https://doi.org/10.1348/026151009X457550d

Ryburn, B., Anderson, V., \& Wales, R. (2009). Asperger syndrome: How does it relate to non -verbal learning disability?. Journal of neuropsychology, 3(1), 107-123. https://doi.org/10.1348/174866407X272448.

Samson, A. C., Huber, O., \& Gross, J. J. (2012). Emotion regulation in Asperger's syndrome and high functioning autism. Emotion, 12(4), 659. https://doi.org/10.1348/174866407X272448

Schneider, N., \& Goldstein, H. (2010). Using Social stories and visual schedules to improve socially appropriate behaviors in children with autism. Journal of Positive Behavior Intervention, 12(3), 149-160. https://doi.org/10.1177/1098300709334198

Schultz, D., Izard. E., Ackerman, B.P., \& Youngstrom, E. A. (2001). Emotion knowledge in economically disadvantaged children: Selfregulatory antecedents and relations to social difficulties and withdrawal. Developmental and Psychopathology, 13, 53-67. https://doi.org/313444E108A50E571CBC5F7951AB7902

Spezio, M. L., Adolphs, R., Hurley, R. S. E., \& Piven, J. (2007). Abnormal use of facial information in high-functioning autism. Journal of Autism and Developmental Disorders, 37, 929-939. https://doi.org/10.1007/s10803-006-0232-9

Spreen, O. (1988). Prognosis of learning disability. Journal of consulting and clinical psychology, 56(6), 836. https://doi.org/10.1037/0022-006X.56.6.836

Sullivan C.A.C., Vitello S.J., \& Foster W. (1988) Adaptive behavior of adults with mental retardation in a group home: an intensive case study. Education and Training in Mental Retardation, March, 76-81.

Weiss, E. (1984). Learning disabled children's understanding of social interactions of peers. Journal of Learning Disabilities, 17, 612-615. https://doi.org/10.1177/002221948401701008

Whiting, P. R., \& Robinson, G. L. (2002, July). The interpretation of emotion from facial expression for children with irlen syndrome. Paper presented at the Seventh International Irlen Conference, Vancouver, Canada.

Widen, S. C., \& Russell, J. A. (2013). Children's recognition of disgust in others. Psychological Bulletin, 139(2), 271. https://dx.doi.org/10.1037/a0031640

Wight, M., \& Chapparo, C. (2008). Social competence and learning difficulties: Teacher perceptions. Australian Occupational Therapy Journal, 55(4), 256-265. https://doi.org/10.1111/j.14401630.2007.00706.x

Wing, L., \& Gould, J. (1979). Severe Impairments of Social Interaction and Associated Abnormalities in Children: Epidemiology and Classification. Journal of Autism and Childhood Schizophrenia, 9, 11-29. https://doi.org/10.1007/BF01531288

Yildirim, A., \& Simsek, H. (2008). Qualitative research methods. Ankara: Seçkin Publisher.

Zuckerman, M., \& Przewuzman, S. J. (1979). Decoding and encoding facial expressions in preschool age children. Journal of Nonverbal Behavior, 3(3), 147-163. https://doi.org/10.1007/BF01142589 